\title{
Correction to: Driving growth of Mwallets in emerging markets: a retailer's perspective
}

\author{
V. Kumar ${ }^{1,2,3,4} \cdot$ Nandini Nim $^{1} \cdot$ Amalesh Sharma $^{5}$
}

Published online: 10 December 2018

(C) Academy of Marketing Science 2018

\section{Correction to: Journal of the Academy of Marketing Science https://doi.org/10.1007/s11747-018-0613-6}

The Area Editor stated in the article note of the original version of this paper is incorrect. It should be: Editor-in-Chief John Hulland accepted the paper for publication.

Publisher's Note Springer Nature remains neutral with regard to jurisdictional claims in published maps and institutional affiliations.

The online version of the original article can be found at https://doi.org/ 10.1007/s11747-018-0613-6

V. Kumar

vk@gsu.edu

Nandini Nim

nnim1@gsu.edu

Amalesh Sharma

asharma@mays.tamu.edu

1 J. Mack Robinson College of Business, Georgia State University, Atlanta, GA, USA

2 Huazhong University of Science and Technology, Wuhan, China

3 Indian School of Business, Hyderabad, India

4 Hagler Institute for Advanced Study, TAMU, College Station, TX, USA

5 Texas A\&M University, College Station, TX, USA 